\title{
Variability of high risk HPV genotypes among HIV infected women in Mwanza, Tanzania- the need for evaluation of current vaccine effectiveness in developing countries
}

Fridolin Mujuni ${ }^{1}$, Mariam M. Mirambo ${ }^{2 *}$, Peter Rambau ${ }^{3}$, Korn Klaus ${ }^{4}$, Muller Andreas ${ }^{5}$, Dismas Matovelo ${ }^{1}$, Mtebe Majigo ${ }^{6}$, Christa Kasang ${ }^{5}$ and Stephen E. Mshana ${ }^{2^{*}}$

\begin{abstract}
Background: High risk (HR) human papilloma Virus (HPV) genotypes have been associated with cervical cancer. In Tanzania there is a limited data on the epidemiology of HPV and genotypes distribution among HIV infected women. Here we document varieties of HPV genotypes associated with cervical squamous intraepithelial lesions (SIL) among HIV- infected women at Bugando Medical Centre, Mwanza-Tanzania.

Methods: A cross sectional hospital based study involving HIV infected women was conducted between August and October, 2014. Exfoliated cells from ectocervix and endocervix were collected using cytobrush. HPV genotypes were detected using polymerase chain reaction (PCR) followed by sequencing using specific primers targeting broad range of HPV types. Cytology was done to establish squamous intraepithelial lesions. Log binomial regression analysis was done to establish risk ratios (RR) associated with HPV infection using STATA version 11.

Results: A total of 255 HIV infected women with mean age $39.2 \pm 9.1$ years were enrolled in the study. HPV DNA was detected in 138/255 (54.1\%, $95 \%$ Cl: 47-60) of HIV infected women. Twenty six genotypes were detected in various combinations; of these 17(65.3\%) were of HR genotypes. HR genotypes were detected in 124(48.6\%) of HIV infected women. Common HR genotypes detected were HPV-52(26), HPV-58(21), HPV-35(20) and HPV-16(14). The risk of being HPV positive was significantly higher among women with CD4 counts $<100$ (RR: 1.20, $95 \%$ Cl: $1.05-1.35, P=0.006$ ) and women with SIL (RR: $1.37,95 \% \mathrm{Cl}: 1.11-1.68, P=0.005)$
\end{abstract}

Conclusion: Significant proportion of HIV infected women with low CD4 counts have various grades of cervical SIL associated with varieties of uncommon HR genotypes. There is a need to evaluate the effectiveness of the current vaccine in preventing cervical cancer in developing countries where HIV is endemic.

Keywords: HPV, HIV, High risk genotypes, Mwanza

Abbreviations: ART, Anti-Retroviral Therapy; BMC, Bugando Medical Centre; CD4, Cluster of Differentiation type 4; CTC, Care and Treatment Clinics; CUHAS, Catholic University of Health and Allied Sciences; HAART, Highly Active Ant-Retroviral Therapy; SIL, Squamous Intraepithelial Lesions; HIV, Human Immunodeficiency Virus; HPV, Human Papilloma Virus; HR, High Risk; LR, Low Risk; RR, Risk ratio; SIL, Squamous Intraepithelial Lesion; SES, Social Economic Status; WHO, World Health Organization

\footnotetext{
*Correspondence: mmmirambo@gmail.com; mshana72@yahoo.com

${ }^{2}$ Department of Microbiology and Immunology, Weill Bugando School of

Medicine, P.O.Box 1464, Mwanza, Tanzania

Full list of author information is available at the end of the article
} 


\section{Background}

Human papillomavirus (HPV) is a very common sexually transmitted infection which is acquired through body fluids and skin-to-skin contact [1]. It has been known as the causal agent of cervical cancer [2]. In sub-Saharan Africa, the incidence of cervical cancer has reached up to 40.7 cases per 100,000 women and it is the second cause of death among cancers affecting women [3, 4]. In HIV infected women the risk of acquiring HPV is even higher due to immune suppression caused by HIV infection which has the same epidemiological pattern as HPV in sub-Saharan Africa $[5,6]$. In most of these cases infection with multiple genotypes has been found to predominate [5, 7-13].

Using molecular techniques, different HPV genotypes have been identified and categorized as high risk (HR) genotypes that are considered to be carcinogenic. These include HPV- $16,18,31,33,35,95,45,51,52,56,58$, $59,68,73$ and 82 ; and are considered to cause approximately $95 \%$ of cervical cancers [14]. Human papilloma virus genotypes $6,11,40,42,43,44,54,61,70,72,81$, and cp 6108 have been classified as low risk (LR); majority of these have been found to cause genital warts [15]. Vaccines for HPV are available in some countries and have been found to be effective in reducing infection and its associated consequences [16].

As reported earlier in Africa, women particularly those who are HIV infected are under-represented in the global estimate of HPV genotypes [17]. This necessitates the need to emphasize HPV screening programs for understanding its epidemiology and effective control. Here we document varieties of HPV genotypes associated with cervical squamous intraepithelial lesions (SIL) and associated factors among HIV- infected women at Bugando Medical Centre, Mwanza-Tanzania underscoring the importance of focused control strategies to prevent cervical cancer in developing countries.

\section{Methods}

\section{Study design, site and population}

A cross sectional hospital based study involving 255 HIV infected women was conducted between August and October, 2014 at Bugando Medical Centre (BMC) HIV care and treatment clinic (CTC). The clinic attends patients who are on antiretroviral therapy (ART) and those who have not started ART. The CTC provides routine Papanicolaou (PAP) smear and gynaecological services with no routine screening of HPV. An average of 80 revisiting HIV infected women are seen per day [18].

Patient selection, socio-demographic and clinical information The study included all HIV infected women aged $>18$ years attending the CTC during the study period while excluding women who underwent wedge resection of the cervix and those with missed CD4 counts within 3 months of specimen collection. Socio-demographic and relevant clinical information collected were number of sexual partners, parity, marital status, age at 1st sexual debut, history of STI, history of genital warts, contraceptive use, and CD4 counts.

\section{Sample collection and Laboratory procedures}

Cervical exfoliated cells from the ectocervix and endocervix were obtained using cytobrush; there after the tip of the cytobrush was placed into a transport medium and stored at $-10{ }^{\circ} \mathrm{C}$ until processing. Papanicolaou (PAP) smear was also taken, processed and interpreted based on the revised 2001 Bethesda system [19].

\section{Detection of HPV DNA}

After vigorous vortexing of transport media, cytobrush was removed and $200 \mu \mathrm{l}$ of sample was used for nucleic acid extraction with the MagNaPure LC DNA Large Volume Kit on a MagNaPure LC instrument (Roche Diagnostics, Mannheim, Germany) with elution volume set at $100 \mu \mathrm{l}$. For the detection of HPV DNA, two different end-point PCR assays (GEN-1 and GEN-2) were done as previously described [20]. Both assays were done using primers targeting sequences which are conserved among a broad range of HPV genotypes, including all major genital HPV genotypes (Tables 1 and 2). These primers amplify fragments of approximately 460 bp for GEN-1 and 220 bp for GEN-2. All PCR products were sequenced (Eurofins Genomics, Ebersberg, Germany); for sequencing of the GEN-1 PCR products, only primer CP4 was used, whereas for GEN-2 PCR products both PPF1 and PPR2 primers were used as previously described [20]. After editing the sequence files using Vector NTI Advance 9 software (Life Technologies, Darmstadt, Germany), sequences were subjected to BLAST search (http://blast.ncbi.nlm.nih.gov/Blast.cgi) to identify the HPV genotypes. The efficiency of nucleic acid extraction was controlled by a real-time PCR assay from our routine diagnostics simultaneously targeting human cytomegalovirus (HCMV) and the human albumin gene.

Table 1 Sequences of primers and probes for HPV detection and controls

\begin{tabular}{cll}
\hline Name & Sequence & Target \\
\hline HPV GEN1 PCR & & \\
CP4 & 5'-ATG GTA CAR TGG GCA & HPV E1 (nt 1942-1961) \\
& TWT GA-3' & \\
CP5 & 5'-GAG GYT GCA ACC AAA & HPV E1 (nt 2400-2378) \\
& AMT GRC-3' \\
HPV GEN2 PCR & \\
PPF1 & 5'-AAC AAT GTG TAG ACA & HPVE1 (nt 2082-2108) \\
& TTA TAA ACG AGC-3' & \\
PPR2 & 5'-ATT AAA CTC ATT CCA & HPVE1 (nt 2336-2314) \\
& AAA TAT GA-3' & \\
\hline
\end{tabular}

Numbering is according to the sequence of HPV16W12E (GenbankIDNr. AF125673) 
Table 2 Socio-demographic \& Reproductive characteristics of the study population

\begin{tabular}{|c|c|c|}
\hline Characteristics & Frequency/mean/median & Percentage (\%) \\
\hline${ }^{a}$ Age(years) & $39.2 \pm 9.1$ & \\
\hline${ }^{\mathrm{b}}$ ARV duration(years) & 3(IQR:1-6) & \\
\hline \multicolumn{3}{|l|}{ Residence } \\
\hline Rural & 158 & 62.0 \\
\hline Urban & 97 & 38.0 \\
\hline \multicolumn{3}{|l|}{ SES } \\
\hline Low & 117 & 45.9 \\
\hline High & 138 & 54.1 \\
\hline \multicolumn{3}{|l|}{$\mathrm{H} / \mathrm{STI}$} \\
\hline NO & 213 & 83.5 \\
\hline YES & 42 & 16.5 \\
\hline \multicolumn{3}{|l|}{ Parity } \\
\hline Nullporous & 24 & 9.4 \\
\hline$\geq 1$ child & 231 & 90.6 \\
\hline \multicolumn{3}{|l|}{ Level of education } \\
\hline Lower level & 209 & 81.7 \\
\hline High level & 46 & 18.3 \\
\hline \multicolumn{3}{|l|}{ CD4 cells/ $\mu \mathrm{l}$} \\
\hline$>200$ & 134 & 52.6 \\
\hline $200-100$ & 99 & 38.8 \\
\hline$<100$ & 22 & 8.6 \\
\hline
\end{tabular}

Age at first intercourse

Below 18

Above $18 \quad 74$

Contraceptive use

None 164

Hormonal

Condom

$$
62
$$

Marital status

\begin{tabular}{lll} 
Not married & 144 & 56.5 \\
Married & 111 & 43.5 \\
ARV use & & \\
None & 24 & 9.4 \\
$\leq 6$ months & 23 & 9.0 \\
$>6$ months & 208 & 81.6 \\
\hline
\end{tabular}

${ }^{\mathrm{a}}$ mean, ${ }^{\mathrm{b}}$ median

\section{Data analysis}

The data were entered in the computer using Microsoft excel software and analysed using STATA version 11(STATA Corp LP, USA). Continuous variables were summarized as mean with standard deviation or as median with interquartile range whilst categorical variables were summarized as proportions. Socioeconomic status (SES) was defined using education, employment and business status of the participant. Log binomial regression for estimation of relative risk ratios was done followed by log multinomial regression analysis for the factors with $P$ value of $<0.2$. Cross tabulation was done to detect variables with collinearity. Factors found with collinearity were not subjected into log multinomial regression analysis. The chi square test and fisher's exact test were done to compare the distribution of HPV genotypes and SIL. Women with mixed genotypes were regarded as having HR genotype if HR genotype was present. Level of significance was measured by $p$-value whereby factors with $p$-values of less than 0.05 were considered statistically significant.

\section{Results}

\section{Sociodemographic and obstetric characteristics}

The mean age of enrolled women was $39.2 \pm 9.14$ years. A total of $111(43.5 \%)$ were married and 46 (18.03\%) and $209(81.7 \%)$ had higher and lower education respectively. Majority of the enrolled women 138(54.1 \%) had

Table 3 Genotypes distribution of HPV

\begin{tabular}{|c|c|c|}
\hline HPV genotypes & Frequency & $\mathrm{LR} / \mathrm{HR}$ \\
\hline HPV 6 & 1 & $L R$ \\
\hline HPV 16 & 14 & $H R$ \\
\hline HPV 18 & 8 & $H R$ \\
\hline HPV 31 & 9 & $H R$ \\
\hline HPV 33 & 4 & $\mathrm{HR}$ \\
\hline HPV 34 & 1 & $H R$ \\
\hline HPV 35 & 20 & $\mathrm{HR}$ \\
\hline HPV 40 & 2 & $L R$ \\
\hline HPV 42 & 5 & LR \\
\hline HPV 45 & 10 & $H R$ \\
\hline HPV 47 & 1 & LR \\
\hline HPV 51 & 3 & $H R$ \\
\hline HPV 52 & 26 & $\mathrm{HR}$ \\
\hline HPV 53 & 5 & $H R$ \\
\hline HPV 54 & 2 & $L R$ \\
\hline HPV 56 & 5 & LR \\
\hline HPV 58 & 21 & $H R$ \\
\hline HPV 59 & 3 & $H R$ \\
\hline HPV 66 & 5 & $\mathrm{HR}$ \\
\hline HPV 68 & 2 & $H R$ \\
\hline HPV 73 & 1 & $\mathrm{HR}$ \\
\hline HPV 74 & 1 & $L R$ \\
\hline HPV 82 & 4 & $H R$ \\
\hline HPV 83 & 3 & $L R$ \\
\hline HPV 90 & 3 & $L R$ \\
\hline HPV 103 & 1 & Unclassified \\
\hline Total & 160 & \\
\hline
\end{tabular}


high socioeconomic status. A total of 158(61.9\%) were residing in rural areas (Table 3 ).

\section{Prevalence of HPV}

Of the 255 enrolled women, 138 (54.1 \%, 95 \% CI: 4760) were found to have HPV DNA in their cervical cells. Out of 138 HPV infected women; 124 (48.6 \%) were found to be infected with HR genotypes.

\section{Genotypes distribution}

In 138 HPV infected women; 26 genotypes were detected in various combinations. A total of 17/138(12.3\%) of HIV infected women had multiple HR genotypes. Of 26 genotypes, $17(65.4 \%$; 95\%CI: 44.7-81.2) were HR while 9 (34.6\%, 95\%CI: $14-49)$ were LR genotypes $(p=0.028)$. High risk genotypes detected were 16, 18, 31, 33, 34, 35, $45,51,52,53,56,58,59,66,68,73$ and 82 whereas LR genotypes detected were $6,40,42,47,54,74,83$ and 90 . The total frequency of the genotypes detected was 160 (Table 4); of these common HR genotypes were HPV52(26, $16.3 \%)$, HPV-58 (21, $13.1 \%)$, HPV-35(20, $12.5 \%)$ and HPV-16(14, $8.8 \%)$.

\section{Cervical squamous intraepithelial lesions (SIL) and genotypes distribution}

Out of the 255 women; 91(35.6 \%) had SIL on cytological studies. Of 91 HIV infected women with SIL, 74 (81.3 \%) had low grade SIL whilst $17(18.7 \%)$ had high grade SIL. Eleven $(64.7 \%)$ of women with high grade SIL had positive HPV DNA in their cervical cells.
Amongst these eleven women none-16 and non-18 genotypes were detected in 9(81.8\%) of them. Out of 124 women infected with HR genotypes, 55 (44.4\%) had any kind of SIL compared to only 31 (26.3\%) of 118 women with no HPV infection $(P=0.003)$ Fig. 1 . Non-significant association between LR genotypes and SIL (5/14 vs. 31/118, $P=0.264$ ) was observed. Of 17 women with multiple high risk genotypes, $1(5.8 \%)$ had high grade SIL, $9(52.9 \%)$ had low grade SIL and 7(41.2 \%) had no SIL.

\section{Factors associated with HPV positivity among HIV infected women}

On $\log$ binomial regression analysis; women with good socioeconomic status, low CD4 counts, use of ARV $\leq 6$ months and presence of SIL significant high risk of HPV infection as shown in Table 4. Only women with low CD4 counts (RR: 1.2, 95 \% CI: 1.05-1.35, $P=$ 0.006 ) and presence of SIL (RR: 1.37, $95 \%$ CI: 1.11-1.68, $P=0.005)$ remained with significant higher risk of being infected with HPV on log multinomial regression analysis.

\section{Discussion}

Infection with oncogenic or HR human papillomavirus (HPV) genotypes is the major cause of cervical cancer. With the introduction of the quadrivalent HPV vaccine which prevents four HPV types: HPV 16 and 18, as well as HPV 6 and 11, that cause $90 \%$ of genital warts the knowledge concerning the distribution of HPV genotypes has become increasingly public health concern [21]. This study for the first time in Mwanza, Tanzania;

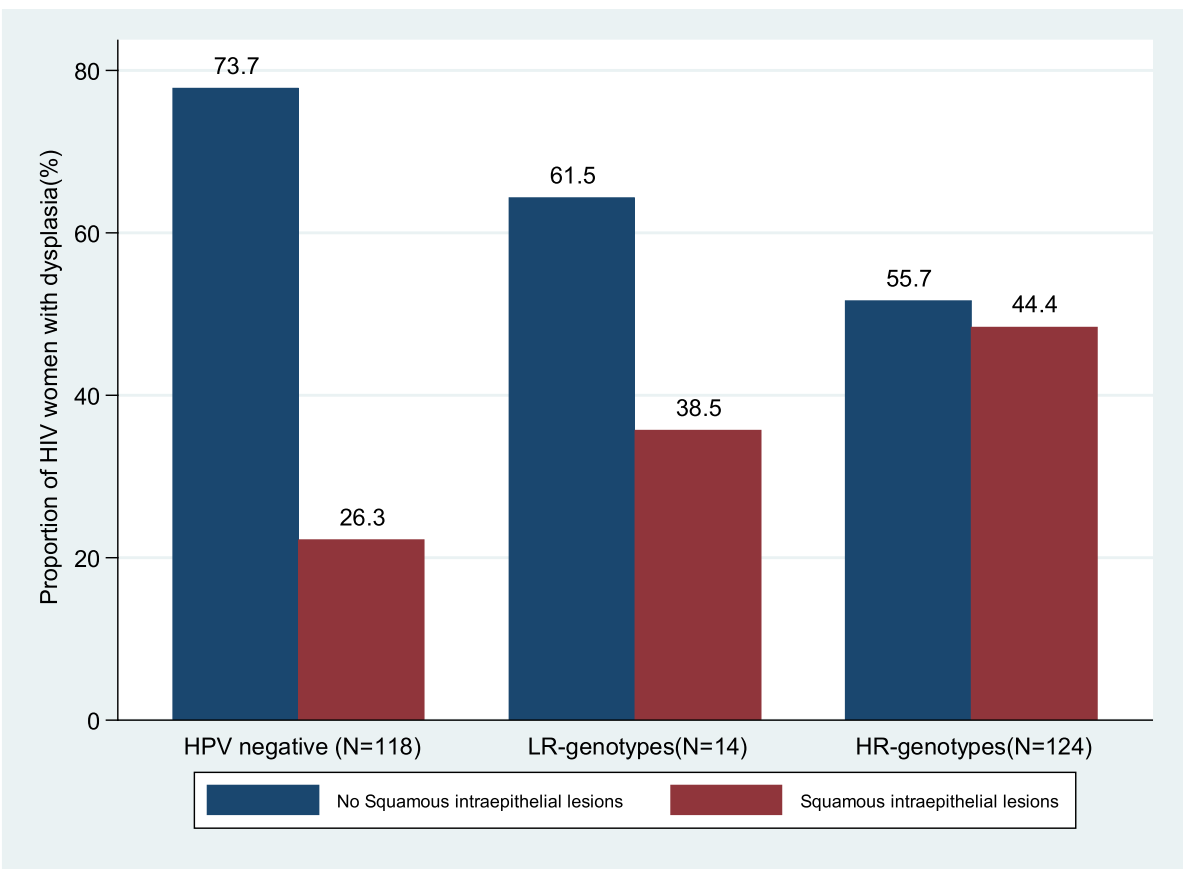

Fig. 1 High risk and low risk HPV genotypes in relation to cervical squamous intraepithelial lesions 
Table 4 Log binomial and log multinomial regression analysis on the factors associated with HPV positivity among HIV infected women

\begin{tabular}{|c|c|c|c|c|c|}
\hline Characteristics & HPV positivity $\%$ & Log binomial RR(95 \% Cl) & $p$ value & Log multinomial RR(95 \% Cl) & $p$-value \\
\hline \multicolumn{6}{|l|}{ Age } \\
\hline$>45(59)$ & $25(42.4 \%)$ & 1 & & & \\
\hline$\leq 45(196)$ & $113(57.6 \%)$ & $1.3(.98-1.87)$ & 0.06 & $1.26(0.89-1.4)$ & 0.266 \\
\hline \multicolumn{6}{|l|}{ Residence } \\
\hline Rural(158) & $85(53.8 \%)$ & 1 & & & \\
\hline Urban(97) & $53(54.64 \%)$ & $1.01(0.80-1.28)$ & 0.896 & & \\
\hline \multicolumn{6}{|l|}{ SES } \\
\hline $\operatorname{Low}(117)$ & $54(46.2 \%)$ & 1 & & & \\
\hline High (138) & $84(60.9 \%)$ & $1.31(1.04-1.67)$ & 0.022 & $1.24(0.97-1.56)$ & 0.064 \\
\hline \multicolumn{6}{|l|}{$\mathrm{H} / \mathrm{STI}$} \\
\hline NO (213) & $111(52.11 \%)$ & 1 & & & \\
\hline YES (42) & $27(64.29 \%)$ & $1.23(0.95-1.599)$ & 0.113 & $1.15(098-1.6)$ & 0.061 \\
\hline \multicolumn{6}{|l|}{ Parity } \\
\hline Nullporous (24) & $14(58.33 \%)$ & 1 & & & \\
\hline$\geq 1$ child (231) & $124(53.68 \%)$ & $0.92(0.64-1.32)$ & 0.650 & & \\
\hline \multicolumn{6}{|l|}{ CD4 } \\
\hline$>200(134)$ & $67(50.00 \%)$ & 1 & & & \\
\hline 200-100(99) & $54(54.55 \%)$ & $1.09(0.85-1.39)$ & 0.490 & & \\
\hline$<100(22)$ & $17(77.27 \%)$ & $1.54(1.16-2.05)$ & 0.003 & $1.20(1.05-1.35)$ & 0.006 \\
\hline \multicolumn{6}{|l|}{ Age at first intercourse } \\
\hline Below 18 (181) & $96(53.04 \%)$ & 1 & & & \\
\hline Above 18 (74) & $42(56.76 \%)$ & $1.07(0.84-1.36)$ & 0.582 & & \\
\hline \multicolumn{6}{|l|}{ Marital status } \\
\hline Not married (144) & $76(52.78 \%)$ & 1 & & & \\
\hline Married (111) & $62(55.86 \%)$ & $1.05(0.84-1.32)$ & 0.623 & & \\
\hline \multicolumn{6}{|l|}{${ }^{\mathrm{a} A R V}$ use } \\
\hline$>6$ months(208) & $117(51.44 \%)$ & 1 & & & \\
\hline$\leq 6$ months $(23)$ & $16(69.5 \%)$ & $1.28(1.00-1.036)$ & 0.049 & & \\
\hline \multicolumn{6}{|l|}{ SIL } \\
\hline Absent (164) & $78(47.5 \%)$ & 1 & & & \\
\hline Present (91) & $60(65.9 \%)$ & $1.49(1.18-1.87)$ & 0.001 & $1.37(1.11-1.68)$ & 0.005 \\
\hline \multicolumn{6}{|l|}{ Contraceptive use } \\
\hline None (164) & $87(53.5 \%)$ & 1 & & & \\
\hline Hormonal (62) & $32(51.6 \%)$ & $0.9729(0.73-1.288)$ & 0.848 & & \\
\hline Condom(29) & 19 (65.5\%) & $1.23(0.914-1.66)$ & 0.219 & & \\
\hline
\end{tabular}

${ }^{a}$ ARV use was not subjected into multivariate analysis because of its collinearity with CD4 counts,

documents high proportion of HIV infected women carrying varieties of HR genotypes similarly to previous reports $[6,22,23]$. As in previous studies [24], a significant proportion of women were uncommonly infected with multiple HR genotypes. These findings are in agreement with previous studies which reported uncommon HR genotypes infecting HIV infected women in developing countries $[4,22,25,26]$. This calls for the need to include uncommon high risk genotypes in the current vaccine production especially for areas where HIV is endemic. The recently introduced a 9 valent (nanovalent) vaccine which includes HPV 52, 58, 45[27]; the commonest genotypes detected in this study is of great advancement especially in sub Saharan Africa where HIV is endemic. The World health organization (WHO) should consider advocating replacing the 
current quadrivalent vaccine which is available in many centers in developing countries with nanovalent vaccine. One of the interesting findings in this study is the presence of HPV 35 genotype in relative high frequency which has been also found in other African countries $[22,26,28]$. Unexpectedly, the recent introduced nanovalent vaccine does not include HPV 35 genotype emphasing the need to use epidemiological data for future vaccine development.

Variation of HPV genotypes can occur even within the country which might have implication in vaccine efficacy in the same country. As evidenced by the fact that in the current study, HPV-16 was not the commonest genotype among women with high grade SIL while in the previous study in Tanzania among HIV and non HIV infected women HPV-16 was the commonest genotype among women with high grade SIL [12]. There is a possibility that the current existing HPV vaccines might have diverse efficacy especially in developing countries.

The current study confirms the clear association between HPV infection and SIL. As in previous studies [29-31], it was observed that women infected with HR genotypes were more likely to have SIL than noninfected and those infected with LR genotypes. Though none of the women with LR genotypes had high grade SIL; it was observed that $35.7 \%$ of women infected with LR genotypes had low grade SIL, following these women over time to determine cervical changes and acquisition of other genotypes will provide important information regarding the role of LR genotypes and SIL. In addition, women with low CD4 counts $(<100)$ had significantly higher risk of acquiring HPV infection (low and high risk genotypes) as compared to their counterparts. Our findings are similar to what have been reported earlier [11, 32-34]. This is due to immune suppression which poses the risk of opportunistic infections including HPV.

The major limitation of this study is inability to perform HIV viral load which could be used to correlate virological failure and HPV infection. In addition some important information such as tobacco use and information for those who declined were not collected. However the study established HPV prevalence and genotypes distribution among HIV infected women.

\section{Conclusion}

In present study, HIV seropositive women with low CD4 counts and various grades of cervical SIL are significantly infected with HR HPV genotypes. In countries where HIV is endemic the governments should consider addition of HPV vaccine in national immunization programme focusing on epidemiology of HPV genotypes. Data on the efficacy of the current vaccine in preventing SIL/cancer and warts are highly needed in developing countries for appropriate policy decision making.

\section{Acknowledgements}

The authors would like to acknowledge the support provided by CTC authority and Institute of clinical and molecular virology, Enlargen University, Schlossgarten for their technical support.

\section{Funding}

This study was supported by research grant from CUHAS to FM and Medical Mission Institute of Wuerzburg. Funders had no any role in this study.

Availability of data and materials

All data have been included in the manuscript.

\section{Authors' contributions}

MMM, DM, CK and SEM participated in the design of the work. FM and DM participated in the collection of specimens and clinical data. FM KK, PR and AM performed laboratory analysis of the specimens. MMM, MM and SEM analyzed and interpreted the data. MMM and SEM wrote the first draft of the manuscript. MMM and SEM did critical revision of the manuscript. All authors read and approved the final version of the manuscript.

\section{Authors' information}

None.

\section{Competing interests}

The authors declare that they have no competing interests.

\section{Ethics approval and consent to participate}

The ethical clearance for the study (CREC/057/2014) was granted by the Joint catholic university of health and allied sciences/Bugando Medical Centre (CUHAS/BMC) research ethics and review committee (CREC). Importance of the study was explained to the participants and written informed consent was sought from each participant prior to enrolment.

\section{Author details}

'Department of Obstetrics and Gynecology, Weill Bugando School of Medicine, P.O.Box 1464, Mwanza, Tanzania. ${ }^{2}$ Department of Microbiology and Immunology, Weill Bugando School of Medicine, P.O.Box 1464, Mwanza, Tanzania. ${ }^{3}$ Department of Pathology, Weill Bugando School of Medicine, P.O.Box 1464, Mwanza, Tanzania. Institute of Clinical and Molecular Virology, Enlargen University, Schlossgarten 4, 91054 Erlangen, Germany. ${ }^{5}$ Medical Mission Institute, Salvatorstrasse 7, 97067 Wuerzburg, Germany. ${ }^{6}$ Department of Microbiology and Immunology, Muhimbili University of Health and Allied Sciences, P.O. Box 65001, Dar es Salaam, Tanzania.

Received: 16 February 2016 Accepted: 6 August 2016

Published online: 19 August 2016

\section{References}

1. Cox JT. Epidemiology and natural history of HPV. J Fam Pract. 2006;21:3-9.

2. WHO: ICO HPV Information Centre. WHO/ICO information Centre on Human Papilloma Virus (HPV) and cervical Cancer centre. 2010.

3. Parkin DM, Bray F, Ferlay J, Pisani P. Global cancer statistics, 2002. CA Cancer J Clin. 2005;55(2):74-108

4. Castellsague X, de Sanjose S, Aguado T: HPV and Cervical Cancer in The World, 2007 Report. WHO/ICO Information Centre on HPV and Cervical Cancer (HPV Information Centre). Geneva: WHO; Barcelona: ICO. In.; 2010

5. Clifford GM, Goncalves MAG, Franceschi S, HPV, group Hs. Human papillomavirus types among women infected with HIV: a meta-analysis. Aids. 2006;20(18):2337-44.

6. Konopnicki D, Manigart Y, Gilles C, Barlow P, De Marchin J, Feoli F, Larsimont D, Delforge M, De Wit S, Clumeck N: High-risk human papillomavirus infection in HIV-positive African women living in Europe. Journal of the International AIDS Society 2013, 16(1).

7. Sahasrabuddhe V, Mwanahamuntu MH, Vermund S, Huh W, Lyon M, Stringer J, Parham G. Prevalence and distribution of HPV genotypes among HIV-infected women in Zambia. Br J Cancer. 2007;96(9):1480-3.

8. Heard I, Tassie J-M, Schmitz V, Mandelbrot L, Kazatchkine MD, Orth G. Increased risk of cervical disease among human immunodeficiency virus-infected women with severe immunosuppression and high human papillomavirus load. Obstet Gynecol. 2000;96(3):403-9. 
9. De Vuyst H, Mugo N, Chung M, McKenzie K, Nyongesa-Malava E, Tenet V, Njoroge J, Sakr S, Meijer CM, Snijders P. Prevalence and determinants of human papillomavirus infection and cervical lesions in HIV-positive women in Kenya. Br J Cancer. 2012;107(9):1624-30.

10. Firnhaber C, Zungu K, Levin S, Michelow P, Montaner LJ, McPhail P, Williamson A, Allan BR, Van der Horst C, Rinas A. Diverse and high prevalence of human papillomavirus associated with a significant high rate of cervical dysplasia in human immunodeficiency virus-infected women in Johannesburg, South Africa. Acta Cytol. 2009;53(1):10-7.

11. MacLeod IJ, O'Donnell B, Moyo S, Lockman S, Shapiro RL, Kayembe M, van Widenfelt E, Makhema J, Essex M, Wester C. Prevalence of human papillomavirus genotypes and associated cervical squamous intraepithelial lesions in HIV-infected women in Botswana. J Med Virol. 2011;83(10):1689-95.

12. Dartell M, Rasch V, Kahesa C, Mwaiselage J, Ngoma T, Junge J, Gernow A, Ejlersen SF, Munk C, Iftner T. Human papillomavirus prevalence and type distribution in 3603 HIV-positive and HIV-negative women in the general population of Tanzania: the PROTECT study. Sex Transm Dis. 2012:39(3):201-8.

13. Assoumou SZ, Mbiguino AN, Mabika BM, Ogoula SN, El Mzibri M, Khattabi A, Ennaji MM. Human papillomavirus genotypes distribution among Gabonese women with normal cytology and cervical abnormalities. Infectious Agents Cancer. 2016;11(1):1-8.

14. Moore RA, Ogilvie G, Fornika D, Moravan V, Brisson M, Amirabbasi-Beik M, Kollar A, Burgess T, Hsu R, Towers L, et al. Prevalence and type distribution of human papillomavirus in 5,000 British Columbia women-implications for vaccination. Cancer Causes Control. 2009;20(8):1387-96

15. Munoz N, Bosch FX, de Sanjose S, Herrero R, Castellsague X, Shah KV, Snijders PJ, Meijer CJ. Epidemiologic classification of human papillomavirus types associated with cervical cancer. N Engl J Med. 2003;348(6):518-27.

16. Organization WH. WHO position on HPV vaccines. Vaccine. 2009;27(52):7236-7.

17. Luque AE, Hitti J, Mwachari C, Lane C, Messing S, Cohn SE, Adler D, Rose R, Coombs R. Prevalence of human papillomavirus genotypes in HIV-1-infected women in Seattle, USA and Nairobi, Kenya: results from the Women's HIV Interdisciplinary Network (WHIN). Int J Infect Dis. 2010;14(9):e810-4.

18. Tanzania Commission for AIDS ZAC, National Bureau of Statistics, Office of the Chief Government Statistician, Inter-national I: Tanzania HIV/AIDS and Malaria Indicator Survey 2007-08. In.: TACAIDS, ZAC, NBS, OCGS, and Macro International Inc Dar es Salaam, Tanzania; 2008.

19. Apgar BS, Zoschnick L, Wright Jr TC. The 2001 Bethesda System terminology. Am Fam Physician. 2003;68(10):1992-8.

20. Petry K, Menton S, Menton M, van Loenen-Frosch F, de Carvalho GH, Holz B, Schopp B, Garbrecht-Buettner S, Davies P, Boehmer G. Inclusion of HPV testing in routine cervical cancer screening for women above 29 years in Germany: results for 8466 patients. Br J Cancer. 2003;88(10):1570-7.

21. Markowitz LE, Dunne $E$, Saraiya M, Lawson $H$, Chesson $H$, Unger E. Quadrivalent human papillomavirus vaccine. Morb Mortal Wkly Rep. 2007;56(RR-2):1-24.

22. Didelot-Rousseau M-N, Nagot N, Costes-Martineau V, Valles X, Ouedraogo A, Konate I, Weiss HA, Van de Perre P, Mayaud P, Segondy M. Human papillomavirus genotype distribution and cervical squamous intraepithelial lesions among high-risk women with and without HIV-1 infection in Burkina Faso. Br J Cancer. 2006;95(3):355-62.

23. Luque $A E$, Jabeen $M$, Messing $S$, Lane CA, Demeter LM, Rose RC, Reichman RC. Prevalence of human papillomavirus genotypes and related abnormalities of cervical cytological results among HIV-1-Infected Women in Rochester, New York. J Infect Dis. 2006;194(4):428-34.

24. Levi JE, Kleter B, Quint WG, Fink MC, Canto CL, Matsubara R, Linhares I, Segurado A, Vanderborght B, Neto JE. High prevalence of human papillomavirus (HPV) infections and high frequency of multiple HPV genotypes in human immunodeficiency virus-infected women in Brazil. J Clin Microbiol. 2002;40(9):3341-5.

25. Strickler HD, Palefsky JM, Shah KV, Anastos K, Klein RS, Minkoff H, Duerr A, Massad LS, Celentano DD, Hall C. Human papillomavirus type 16 and immune status in human immunodeficiency virus-seropositive women. J Natl Cancer Inst. 2003:95(14):1062-71.

26. Castellsagué X, Klaustermeier J, Carrilho C, Albero G, Sacarlal J, Quint W, Kleter B, Lloveras B, Ismail MR, de Sanjosé S. Vaccine-related HPV genotypes in women with and without cervical cancer in Mozambique: Burden and potential for prevention. Int J Cancer. 2008;122(8):1901-4.
27. Joura EA, Giuliano AR, Iversen O-E, Bouchard C, Mao C, Mehlsen J, Moreira Jr ED, Ngan Y, Petersen LK, Lazcano-Ponce E. A 9-valent HPV vaccine against infection and intraepithelial neoplasia in women. N Engl J Med. 2015;372(8): 711-23.

28. Denny L, Adewole I, Anorlu R, Dreyer G, Moodley M, Smith T, Snyman L, Wiredu E, Molijn A, Quint W. Human papillomavirus prevalence and type distribution in invasive cervical cancer in sub-Saharan Africa. Int J Cancer. 2014;134(6):1389-98.

29. Schäfer A, Friedmann W, Mielke M, Schwartländer B, Koch MA. The increased frequency of cervical dysplasia-neoplasia in women infected with the human immunodeficiency virus is related to the degree of immunosuppression. Am J Obstet Gynecol. 1991;164(2):593-9.

30. Schlecht NF, Kulaga S, Robitaille J, Ferreira S, Santos M, Miyamura RA, Duarte-Franco E, Rohan TE, Ferenczy A, Villa LL. Persistent human papillomavirus infection as a predictor of cervical intraepithelial neoplasia. JAMA. 2001;286(24):3106-14.

31. Koshiol J, Lindsay L, Pimenta JM, Poole C, Jenkins D, Smith JS. Persistent human papillomavirus infection and cervical neoplasia: a systematic review and meta-analysis. Am J Epidemiol. 2008;168(2):123-37.

32. Palefsky JM, Minkoff H, Kalish LA, Levine A, Sacks HS, Garcia P, Young M, Melnick S, Miotti P, Burk R. Cervicovaginal human papillomavirus infection in human immunodeficiency virus-1 (HIV)-positive and high-risk HIV-negative women. J Natl Cancer Inst. 1999;91(3):226-36.

33. Dames DN, Blackman E, Butler R, Taioli E, Eckstein S, Devarajan K, GriffithBowe A, Gomez P, Ragin C, Consortium ACC. High-risk cervical human papillomavirus infections among human immunodeficiency virus-positive women in the Bahamas. PLoS One. 2014;9(1), e85429.

34. Dames DN, Ragin C, Griffith-Bowe A, Gomez P, Butler R. The prevalence of cervical cytology abnormalities and human papillomavirus in women infected with the human immunodeficiency virus. Infect Agent Cancer. 2009;4 Suppl 1:S8.

\section{Submit your next manuscript to BioMed Central and we will help you at every step: \\ - We accept pre-submission inquiries \\ - Our selector tool helps you to find the most relevant journal \\ - We provide round the clock customer support \\ - Convenient online submission \\ - Thorough peer review \\ - Inclusion in PubMed and all major indexing services \\ - Maximum visibility for your research}

Submit your manuscript at www.biomedcentral.com/submit
C Biomed Central 